\begin{tabular}{|c|l|}
\hline Title & A NOTE ON MODELLING ENDOGENOUS GROWTH \\
\hline Sub Title & \\
\hline Author & SATO, Ryuzo \\
\hline Publisher & Keio Economic Society, Keio University \\
\hline Publication year & 1996 \\
\hline Jtitle & Keio economic studies Vol.33, No.2 (1996.) ,p.93-101 \\
\hline JaLC DOI & \\
\hline Abstract & $\begin{array}{l}\text { The Note explores the conditions for the existence of a steady state in an neo-classical model } \\
\text { with factor-augmenting technical progress. Under the assumption that saving is automatically } \\
\text { invested, I.e., investment is a linear function of output, the Harrod neutral type of technical } \\
\text { progress is the only case consistent with the steady state equilibrium. But for the case of non- } \\
\text { linear investment function which allows for the diminishing returns, the ecomomy with a general } \\
\text { factor augmenting technical progress may be consistent wih the steady state equilibirum. The } \\
\text { necessary condition for this is that the consumption function be homogenous of degree two, or } \\
\text { the investment function of degree zero. This paper presents several sufficient conditions } \\
\text { consistent with the solutions of the optimal control, when the central planner determines the } \\
\text { optimal level of factor-augmenting technical progress. }\end{array}$ \\
\hline Notes & Note \\
\hline Genre & Journal Article \\
\hline URL & $\begin{array}{l}\text { https://koara.lib.keio.ac.jp/xoonips/modules/xoonips/detail.php?koara_id=AA00260492-1996000 } \\
\text { 2-0093 }\end{array}$ \\
\hline
\end{tabular}

慶應義塾大学学術情報リポジトリ(KOARA)に掲載されているコンテンツの著作権は、それぞれの著作者、学会または出版社/発行者に帰属し、その権利は著作権法によって 保護されています。引用にあたっては、著作権法を遵守してご利用ください。

The copyrights of content available on the KeiO Associated Repository of Academic resources (KOARA) belong to the respective authors, academic societies, or publishers/issuers, and these rights are protected by the Japanese Copyright Act. When quoting the content, please follow the Japanese copyright act. 


\title{
A NOTE ON MODELLING ENDOGENOUS GROWTH
}

\author{
Ryuzo SATo \\ Economics Department and Center for Japan-U.S. Business and Economic Studies, \\ Stern School of Business, New York University, New York, U.S.A.
}

First version received February 1995; final version accepted March 1996

\begin{abstract}
The Note explores the conditions for the existence of a steady state in an neo-classical model with factor-augmenting technical progress. Under the assumption that saving is automatically invested, i.e., investment is a linear function of output, the Harrod neutral type of technical progress is the only case consistent with the steady state equilibrium. But for the case of non-linear investment function which allows for the diminishing returns, the ecomomy with a general factor augmenting technical progress may be consistent wih the steady state equilibirum. The necessary condition for this is that the consumption function be homogenous of degree two, or the investment function of degree zero. This paper presents several sufficient conditions consistent with the solutions of the optimal control, when the central planner determines the optimal level of factor-augmenting technical progress.
\end{abstract}

\section{INTRODUCTION}

This note is to explore the conditions for the existence of a steady state in a neo-classical model with factor-augmenting technical progress. While many theoretical and empirical papers have been written elaborating on and testing the neo-classical model, the reason why Harrod-neutral technical progress alone is consistent with steady-state in these models has not been well understood or explained. This is particularly surprising as an earlier tradition in microeconomics has the relative growth in input prices determine bias endogenously.

Incorporating the Hicksian theory of bias in a neo-classical model with full employment poses many problems. Growth models traditionally assume that firms are atomistic; if firms are price takers, Fellner (1961) noted that some type of learning process will have to be postulated to justify such firms investing in biased technical innovations. Salter (1960) argued that firms should minimize total costs and should not be concerned with the cost or price of any one input; Kennedy (1964) responded to Salter's criticism by postulating a static innovation

Acknowledgement. He wishes to acknowledge the helpful comments by Paul A. Samuelson, Rama Ramachandran, Chengping Lian, and the referee of this journal. 
possibility frontier. Kennedy, however, took his theory to imply a rejection of the marginal productivity theory but Samuelson (1965) showed that it is consistent with the neo-classical theory of production [see also Drandakis and Phelps (1965)].

Nordhaus (1967) and Kamien and Schwartz (1969) developed microeconomic models in which the positions of the innovation possibility frontier are endogenously determined. But they did not consider biased technical progress. That step was taken in Sato and Ramachandran (1987). They showed that, in a steady state, the bias in technical progress will just counterbalance the differential growth in factor prices.

Economic historians would argue that, in industrialized countries, the rate of interest is oscillatory but trendless while the wage rate is steadily increasing. These trends in factor prices can be explained by a neo-classical model with Harrod-neutral technical progress if it is assumed that the economy is always in steady state; if the economy is not in steady state, the stylized facts are not consistent with the model. The assumption that the economy is in steady state throughout the nineteenth and twentieth centuries is indeed a strong one. A model of endogenous bias can be made to generate the stylized facts even outside the steady state.

But the estimation of biased technical progress poses some well-known problems. The Diamond-McFadden theorem states that we cannot simultaneously estimate bias and elasticity. To break this impasse, Sato (1970) derived the Constant Elasticity of Derived Demand production function which has a convenient property that the elasticity of substitution is proportional to factor share. Estimation using U.S. non-farm data for 1909 to 1960 showed that the function fitted the data better than the Cobb-Douglas production function and that technical progress was labor saving. It also indicated that a rising trend in capital-labor ratio and constant interest rate and rising wage rate are not inconsistent. If $Y=$ $F(A K, B L)=B L \cdot f(A K / B L)=B L \cdot f(\bar{k})$, where $\bar{k}=A K / B L$ then $\partial Y / \partial K=A(\mathrm{~d} f /$ $\mathrm{d} \bar{k})=A f^{\prime}(\bar{k})$ can be constant even if $A$ is increasing provided $f^{\prime}$ decreases over time.

A model without technical progress can be formulated as

$$
\begin{gathered}
C=C(K, L: \dot{K}, \dot{L}), \\
\frac{\partial C}{\partial K}>0, \quad \frac{\partial C}{\partial L}>0, \quad \frac{\partial C}{\partial \dot{K}}<0 \text { and } \frac{\partial C}{\partial \dot{L}} \leq 0,
\end{gathered}
$$

where $C$, consumption, which is linear homogeneous in $K, L, \dot{K}$ and $\dot{L}$ and also satisfies other nice properties such as concavity. Here the economic assumption is that the growth of inputs, $K$ and $L$, is achieved through the use of the homogeneous output so that consumption is determined not only by output but also by the rate of growth of $K$ and $L$.

The standard neo-classical growth model assumes that the investment function is "linear," that is, $\partial C / \partial \dot{K}=$ constant, $\partial^{2} C / \partial \dot{K}^{2}=0$ and $\partial C / \partial \dot{L}=0$. Furthermore, saving, which is generated from output, is automatically invested and the labor 
force is exogenously given and growing rate at the rate $n$. Thus

$$
\begin{gathered}
C=F(K, L)-\dot{K}, \\
\dot{K}=s F(K, L), \quad 0<s=\text { saving ratio =const } \quad<1, \\
\dot{L}=n L . \quad n>0 .
\end{gathered}
$$

Now introduce the factor-augmenting type of technical progress in production of output $F$ as

$$
F(A(t) K(t), B(t) L(t)),
$$

where $A(t)$ and $B(t)$ are exogenously given and growing at the rate of $\alpha$ and $\beta$ respectively, i.e.

$$
\begin{aligned}
& A(t)=A(0) \mathrm{e}^{\alpha t}, \\
& B(t)=B(0) \mathrm{e}^{\beta t} .
\end{aligned}
$$

Then the above model will become

$$
\begin{gathered}
C=F(A . K, B . L), \\
\dot{K}=s F(A . K, B . L), \\
\dot{L}=n L .
\end{gathered}
$$

The capital accumulation function,

$$
\frac{\dot{K}}{K}=s F\left(A, \frac{B L}{K}\right)
$$

will be constant in steady state if and only if $F(A, B L / K)$ is constant. This is accomplished for a general class of $F$ if and only if $B L / K=$ constant and $A=$ constant. ${ }^{1}$ This means that in general the Harrod-neutral progress or the laboraugmenting type $(\alpha=0, \beta \neq 0)$ is the only case consistent with the steady state equilibrium. In steady state, the capital accumulation function

$$
\frac{\dot{K}}{K}=s F\left(1, \frac{B L}{K}\right)
$$

is homogeneous function of zero degree with respect to $B, L$, and $K$, and remains constant. This conclusion is valid even if we introduce "endogenous" labor augmenting technical progress as long as the rate of labor augmentation becomes constant in steady state, i.e.,

$$
\lim _{t \rightarrow \infty} \frac{\dot{B}}{B}=\beta
$$

${ }^{1}$ If $F$ is Cobb-Douglas type or the limiting Cobb-Douglas type, where the function approaches to the Cobb-Douglas in the long run, then A need not be constant-a well-known result. 
Next consider the case of "non-linear investment" function. To simplify the analysis, we consider the non-linear "separable" investment function.

$$
C=F(K, L)-G(\dot{K}, \dot{L}, K, L) .
$$

Here $F$ is the traditional production function. An example of a non-linear investment function in literature is [Leviathan and Samuelson (1969)]:

$$
I^{2}=(\dot{K}+\delta K)^{2}+(\dot{L})^{2}=G^{2}
$$

and

$$
C=F-G=F-I=F(1-i)
$$

where a fraction $i$ of $F$ allocated to create $\dot{K}+\delta K$ and $\dot{L}$.

This model can be extended to incorporate factor augmenting technical progress in the production function:

$$
\begin{gathered}
Y=F(A K, B L), \\
C=F(A K, B L)-G .
\end{gathered}
$$

Just as the rate of growth of physical capital is modeled as being determined by a separable investment function, so it is traditional to assume (in models of endogenous technical progress) that the rates of growth of efficiency of inputs are determined by a separable "investment" function. In this paper, we generalize the function, $G(\cdot)$ above, to assume that it determines the growth rates of inputs in both physical and efficiency units through allocation of resources for "investment". Introducing technical progress in the factor augmenting form imposes very strong conditions on the properties of the investment and consumption functions. If the model is to have a steady state equilibrium in the sense that $\lim _{t \rightarrow \infty}(A K / B L)$ is a constant, $G$ has to have functional properties which are compatible with that of $F$.

Note that $F(\cdot)$ is homogeneous of degree two in $\mathrm{A}, K, B$ and $L$. So the necessary condition for the steady state under the factor-augmenting technical progress is that $C=F(\cdot)-G(\cdot)$ is homogeneous of degree two; this would require that $G($ ) is asymptotically homogeneous of degree two with respect to its variables, $A, K$, $B, L, \dot{A}, \dot{K}, \dot{B}$, and $\dot{L}$. Many functions would satisfy this condition; some would have meaningful economic interpretation while others would not. The necessary condition can be written as:

$$
\lambda^{2} C=\lim _{t \rightarrow \infty} C(\lambda A . \lambda K, \lambda B . \lambda L ; \lambda \dot{K}, \lambda \dot{L}, \lambda \dot{A}, \lambda \dot{B}, \lambda K, \lambda L, \lambda A, \lambda B)
$$

An example of a function which satisfies this condition is,

$$
C=F(A K, B L)-A K\left(\frac{\dot{A}}{A}\right)^{2}-A K\left(\frac{\dot{K}}{K}\right)^{2}-B L\left(\frac{\dot{B}}{B}\right)^{2}
$$

Since $C$ is homogeneous of degree two in $A, K, B, L, \dot{K}, \dot{A}$ and $\dot{B}$, and $A, K, B$ 
and $L$ are growing exponentially at $t \rightarrow \infty$, there is a possibility that a steady state exists, with $\lim _{t \rightarrow \infty}(A K / B L)=$ constant.

The sufficient conditions: If any one of the following conditions is satisfied, then $A K / B L$ is constant in steady state;

$$
\lambda^{2} C=C[\lambda A . \lambda K, \lambda B . \lambda L ; \lambda(\dot{A K}), \lambda(\dot{B} L)]
$$

or

$$
\lambda^{2} C=C[\lambda A . \lambda K, \lambda B . \lambda L: \lambda(\dot{A} K), \lambda(\dot{K} A), \lambda(\dot{B} L), \lambda(\dot{L} B), \lambda(\dot{A} \dot{K}), \lambda(\dot{B} \dot{L})]
$$

or

$$
\begin{gathered}
\lambda^{2} C=C\left[\lambda A . \lambda K, \lambda B . \lambda L ; \lambda(A K) \phi_{1}\left(\frac{\dot{A}}{A}\right), \lambda(A K) \phi_{2}\left(\frac{\dot{K}}{K}\right),\right. \\
\left.\lambda(B L) \phi_{3}\left(\frac{\dot{B}}{B}\right), \lambda(B L) \phi_{4}\left(\frac{\dot{L}}{L}\right)\right]
\end{gathered}
$$

There may be many other forms of sufficient conditions but we will list below a few special functions that satisfy any one of the above sufficiency conditions.

(i) We now present three examples which satisfy the sufficient conditions (3), (4) and (5) respectively. The first case is a $G(\cdot)$ function that can be thought of as a generalization, to include technical progress, of the non-linear investment function stated earlier.

$$
C=F(A K, B L)-G[(\dot{A K}),(\dot{B} L)]=(1-i) F, G=i F
$$

where $G^{2}=a(\dot{A K})^{2}+b(\dot{B L})^{2}$

Therefore,

$$
C=F(A K, B L)-\sqrt{\left[a(\dot{A} K+A \dot{K})^{2}+b(\dot{B} L+\dot{L} B)^{2}\right]} .
$$

(ii) The following is an example of (4):

$$
\begin{aligned}
C=F(A K, & B L)-G(.)=F(A K, B L) \\
& -\sqrt{\left[\alpha(\dot{A} K)^{2}+\beta(\dot{K} A)^{2}+\gamma(\dot{B} L)^{2}+\delta(\dot{L} B)^{2}+\xi(\dot{A} \dot{K})^{2}+\eta(\dot{B} \dot{L})^{2}\right]}
\end{aligned}
$$

(iii) A special case of (5) is the additive investment function of neoclassical growth models. The general form that will satisfy the homogeneity condition and the steady-state condition is

$$
C=F(A K, B L)-\left[A K \phi_{1}\left(\frac{\dot{A}}{A}\right)+A K \phi_{2}\left(\frac{\dot{K}}{K}\right)+B L \phi_{3}\left(\frac{\dot{B}}{B}\right)\right] .
$$

In particular, $\phi_{i}$ may take a power function form,

$$
G=I=a A K\left(\frac{\dot{A}}{A}\right)^{\alpha}+b A K\left(\frac{\dot{K}}{K}\right)^{\beta}+c B L\left(\frac{\dot{B}}{B}\right)^{\gamma}
$$


where $\alpha, \beta, \gamma>1$.

An alternative implication of the sufficient condition may be more closely investigated by looking equation (8). The investment function $\dot{K} / K$, and the technical progress functions $\dot{A} / A$ and $\dot{B} / B$ must be of homogeneous degree zero with respect $A, K, B$ and $L$. We have already shown that under the linear investment function $C=F-\dot{K}$, the capital accumulation function, $\dot{K} / K=s F(A, B L / K)$ is of homogenous degree zero with respect to $A, K, B$ and $L$, if and only if $A$ is constant, i.e., the Harrod neutral technical change $\dot{B} / B=\beta>\beta$, and $\dot{L} / L=n$.

We can now formulate an optimal growth model with endogenous technical progress. Given $c=C / L=(F(A K, B L)-G(\dot{K}, \dot{L}, \dot{A}, \dot{B}, K, L, A, B)) / L$ (Here we assume, without loss of generality, that the objective function can be written in a separable form)

$$
\operatorname{Max} \int_{0}^{\infty} \mathrm{e}^{-\rho t} c \mathrm{~d} t
$$

Alternatively the above maximization problem may be written in the form of optimal control as

$$
\underset{u_{1}, u_{2}, u_{3}}{\operatorname{Max}} \int_{0}^{\infty} \mathrm{e}^{-\rho t} c \mathrm{~d} t
$$

s.t.

$$
\begin{aligned}
& \dot{g}_{1}=\left(u_{1}+u_{2}-\varepsilon\right) g_{1} \\
& \dot{g}_{2}=\left(u_{3}+n-\varepsilon\right) g_{2}
\end{aligned}
$$

where

$$
\begin{aligned}
c & =C L^{-1} \\
& =L^{-} . E .\left[F\left(g_{1}, g_{2}\right)-G\left(\frac{\dot{A} K}{E}, \frac{\dot{K} A}{E}, \frac{\dot{B} L}{E}, \frac{\dot{L} B}{E}, \frac{\dot{A} \dot{K}}{E}, \frac{\dot{B} \dot{L}}{E}, \frac{A K}{E}, \frac{B L}{E}\right)\right] \\
& =\mathrm{e}^{-n t} \mathrm{e}^{\varepsilon t}\left[F\left(g_{1}, g_{2}\right)-G\left(u_{1} g_{1}, u_{2} g_{1}, u_{3} g_{2}, n g_{2}, u_{1} u_{2} g_{1}, n u_{3} g_{2} ; g_{1}, g_{2}\right)\right] \\
g_{1} & =\frac{A K}{E}, \quad g_{2}=\frac{B L}{E}, \quad \frac{\dot{A}}{A}=u_{1}, \quad \frac{\dot{K}}{K}=u_{2}, \quad \frac{\dot{B}}{B}=u_{3}, \quad \frac{\dot{L}}{L}=n=\text { const. }
\end{aligned}
$$

and

$$
\frac{\dot{E}}{E}=\varepsilon=\frac{\dot{Y}}{Y}=\frac{\left(A^{*} K^{*}\right)}{A^{*} K^{*}}=\frac{\left(B^{*} L^{*}\right)}{B^{*} L^{*}}=\text { steady-state growth rate of output } Y
$$

In order to solve the above problem, we follow the standard technique of optimal control. Setting

$$
\underset{u_{1}, u_{2}, u_{3}}{\operatorname{Max}} \int_{0}^{\infty} \mathrm{e}^{-(\rho+n-\varepsilon) t} h\left(g_{1}, g_{2}, u_{1}, u_{2}, u_{3}\right) \mathrm{d} t
$$


subject to

$$
\begin{aligned}
& \dot{g}_{1}=\left(u_{1}+u_{2}-\varepsilon\right) g_{1} \\
& \dot{g}_{2}=\left(u_{3}+n-\varepsilon\right) g_{2}
\end{aligned}
$$

we obtain

$$
H=h\left(g_{1}, g_{2} ; u_{1}, u_{2}, u_{3}\right)+p_{1} g_{1}\left(u_{1}+u_{2}-\varepsilon\right)+p_{2} g_{2}\left(u_{3}+n-\varepsilon\right)
$$

The above can be solved to yield the optimal paths of investments in $K, A$ and $B$ [Sato, Ramachandran, and Lian (1993)].

In each period $t \geq 0$, the society chooses an optimal amount of investment I which is allocated among the three sectors that generate $\dot{A} / A, \dot{B} / B$ and $\dot{K} / K$. In a steady state, the investment ratio $i$ takes a constant value of $i=i^{*}$.

This model can be worked out for the various special cases of $G$ function that we have formulated above. As long as $C$ is homogeneous of degree two, the system will have a steady state where the ratio $A K / B L$ is a constant.

Finally we can show that the present model is applicable not only to a Robinson Crusoe economy, i.e., to the economy with an omnipotent capital planner, but also to a decentralized market economy in which consumers are responsible for intertemporal consumption planning and producers are seperately responsible for investment in physical and human capital and technical progress. Let us assume that a constant function of income is invested in $\dot{K}, \dot{A}$, and $\dot{B}$ resectively.

Thus, consider the model:

$$
\begin{gathered}
C=F(A . K, B . L)-\sum_{i=1}^{3} M_{i} \\
M_{i}=s_{i} F(A . K, B . L), \quad 0<s_{i}<1, \quad i=1,2,3 \\
M_{1}=A . K \Phi_{1}\left(\frac{\dot{A}}{A}\right), \\
M_{2}=A . K \phi_{2}\left(\frac{\dot{K}}{K}\right) \quad \phi_{i}^{\prime}>0, \quad \phi_{i}^{\prime \prime}>0 \\
M_{3}=B . L \Phi_{3}\left(\frac{\dot{B}}{B}\right) \\
\dot{L}=n L
\end{gathered}
$$

The model reduces to the following:

$$
\begin{array}{ll}
\frac{\dot{A}}{A}=\psi_{1}\left(\frac{s_{1} F(A . K, B . L)}{A \cdot K}\right), & \psi_{1}=\Phi_{1}^{-1} \\
\frac{\dot{K}}{K}=\psi_{2}\left(\frac{s_{2} F(A . K, B . L)}{A . K}\right), & \psi_{2}=\Phi_{2}^{-1}
\end{array}
$$




$$
\frac{\dot{B}}{B}=\psi_{3}\left(\frac{s_{3} F(A . K, B . L)}{B . K}\right), \quad \psi_{3}=\Phi_{3}^{-1}
$$

Defining $\bar{k}=A . K / B . L$, we have

$$
\frac{\dot{\bar{k}}}{\bar{k}}=\psi_{1}\left(s_{1} f(\bar{k})\right)+\psi_{2}\left(s_{2} f(\bar{k})\right)-\psi_{3}\left(s_{3} g(\bar{k})\right)-n,
$$

where

$$
f(\bar{k})=F\left(1, \frac{1}{\bar{k}}\right) \text { and } g(\bar{k})=F(\bar{k}, 1) .
$$

There exists a steady state equilibrium, i.e., $\dot{\bar{k}}=0$ and $\bar{k}=\bar{k}^{*}$, and the economy is growing at the rate of

$$
\left(\frac{\dot{A}}{A}\right)^{*}+\left(\frac{\dot{K}}{K}\right)^{*}=\left(\frac{\dot{B}}{B}\right)^{*}+n,
$$

where ${ }^{*}$ indicates the steady state value for each variable. The steady state euilibrium is stable, because

$$
\frac{\mathrm{d}\left(\frac{\dot{\bar{k}}}{\bar{k}}\right)}{\mathrm{d} \bar{k}}=s_{1} \psi_{1}^{\prime} f^{\prime}+s_{2} \psi_{2}^{\prime} f^{\prime}-s_{3} \psi_{3}^{\prime} g^{\prime}<0
$$

where

$$
\psi_{i}^{\prime}>0, f^{\prime}<0 \text { and } g^{\prime}>0 .
$$

We can show that the same stable property for a more general case where investment and technical progress functions satisfy the sufficient conditions stated above.

\section{REFERENCES}

Drandakis, E. M. and Phelps, Edward S. "A model of induced innovation, growth and distribution", The Economic Journal, December 1965, 75(300), pp. 823-40.

Fellner, William "Two propositions in the theory of induced innovations", Economic Journal, June 1961, 71(283), pp. 305-8.

Kamien, Morton I. and Schwartz, Nancy. L. "Induced factor augmenting technical progress from a microeconomic viewpoint", Econometrica, September 1969, 37(5), pp. 668-84.

Kennedy, Charles "Induced bias in innovation and the the theory of distribution", Economic Journal, September 1964, 74(295), pp. 541-47.

Leviathan, Nisan and Samuelson, Paul. A. "Notes on turnpikes: Stable and unstable", 1969, Journal of Economic Theory, December 1969, 1(4), pp. 454-75.

Nordhaus, William D. Invention, Growth, and Welfare: A Theoretical Treatment of Technological Change, Cambridge, MA: The M.I.T Press, 1969.

Samuelson, Paul A. "A theory of induced innovation along Kennedy-Weizacker lines", The Review 
of Economics and Statistics, November 1965, 47(4), pp. 343-56.

Salter, W. E. G. Productivity and Technical Change, Cambridge, U.K.: Cambridge University Press, 1960.

Sato, Ryuzo "The estimation of biased technical progress and production function", 1970, International Economic Review, June 1970, 39(2), pp. 343-56.

Sato, Ryuzo and Ramachandran, Rama "Factor price variation and the Hicksian hypothesis: a microeconomic model", Oxford Economic Papers, June 1987, 39(2), pp. 343-56.

Sato, Ryuzo, Ramachandran, Rama, and Lian, Chingpin "A model of optimal economic growth with endogenous bias", Working Paper of the Center for Japan-U.S. Business and Economic Studies, Stern School of Business, New York University, 1993. 